\title{
reviews
}

\section{Best kind of Natural History}

S. R. J. Woodell

Population Biology of Plants. By John L. Harper. Pp. xxiv +892 . (Academic: London, New York and San Francisco, 1977.) £30; $\$ 58.60$.

As Professor Harper states in his preface, population biology was for almost half a century the almost exclusive preserve of zoologists. In the early part of this century, Sukatschew, Tansley and especially Clements experimented on plant populations, but thereafter most plant ecologists turned to other aspects of the subject. This might seem strange. Plants are immobile. They do not have to be captured, marked and recaptured, but whereas animals respond to environmental changes by changing numbers, plants may change in either number or size, or both. It is perhaps this plasticity that has deterred some botanists from studying their populations. Numbers can be counted, size has to be measured, usually destructively.

Harper was fortunate to come into contact early in his career with Charles Elton and his group in Oxford, and then with agronomists in Aberystwyth, to whom experimentation on plant populations was nothing new. Unlike most botanists he realised the relevance of animal population studies to plants, and acted upon it. During the past twenty-five years he, his students and co-workers have done more than anyone to set the science of plant population biology on its feet, and it is appropriate that he should write the first major book about it.

A short introductory chapter on "Experiments, Analogies and Models" sets the scene, and is followed by five major sections: on "Dispersal, Dormancy and Recruitment"; "The Effects of Neighbours"; "The Effects of Predators"; "The Natural Dynamics of Plant Populations"; and finally, "Plants, Vegetation and Evolution".
Each is complete in itself, but they are all linked by the evolutionary theme that pervades the whole book. Harper, in acknowledging his debt to Darwin, states that he thinks the third chapter of the Origin of Species is the best ecological text ever written. Though not all would agree with this, there is no doubt that it shows an insight into interactions between organisms that has not yet been surpassed, for all that it was written 120 years ago. Harper comments (p492): "in ecology . . . the idea of evolution as a continually operating force in ecological interactions seems to be accepted unwillingly." Sadly, this is true of many, though not by any means all ecologists; such workers as G. E. Hutchinson are outstanding exceptions. This book puts the relationship between ecology and evolution firmly back into the centre of the stage.

Every chapter in Harper's book has something to say about how plant populations interact with their total environment. With animal ecologists in mind as readers, he is constantly pointing to ways in which animal and plant populations are similar and different. Apart from the plasticity of plants, two especially interesting points he makes are that the food of green plants does not reproduce and is not the result of a reproductive process (this fundamentally affects their population biology); and that plants consist of "populations of parts" (and this cannot be said of animals except perhaps corals, and some colonial Hymenoptera).

Everyone will find much of interest here; there are ideas enough to keep several workers busy for a lifetime. If I may pick chapters which especially interested me, I would select. chapter 11, "Mechanisms of Interaction Between Species", as a most stimulating, critical and thought-provoking discussion of the problems and pitfalls inherent in studying plant interactions. The several chapters on "The Effects of Predators" comprise an account in depth of some aspects of plantanimal interactions, a fashionable field these days after long neglect. The final section, where evolution is brought to the fore, is a fascinating development in evolutionary terms of much that has gone before.

It will be clear that I liked this book; indeed, I found it difficult to put down once I had begun it. There are small irritations. In places, it reads rather like a catalogue of experiments, though every experiment described is very relevant. Those familiar with Harper's work will be familiar with much of the content of the book, but to have it all together is very valuable; and a glance at the bibliography reveals the breadth of the literature surveyed here. Harper is not quite consistent in his acceptance in some places, and rejection in others, of anecdotal evidence. These are minor flaws. A credit is the inclusion of good chapter summaries at the beginning of the book.

'Natural History' is a much-abused term, probably largely as a result of the flood of poor quality writings on it during the last century. Yet who would deny that The Natural History of Selborne (Gilbert White) is a great book, or that although much of what Darwin wrote was Natural History, he was a great scientist. The Oxford English Dictionary defines Natural History thus: "A work dealing with the properties of natural objects, plants or animals; a scientific account of any subject on similar lines." In those terms, 1 am sure that Professor Harper will not object to his book being described as an example of the best kind of Natural History.

S. R. J. Woodell is Lecturer in Ecology in the Botany School at the University of Oxford, UK. 